\title{
Nombramiento del árbitro por las cámaras de comercio
}

\author{
Mario Castillo Freyre \\ Jhoel Chipana Catalán
}

\section{Generalidades}

El artículo 25 de la Ley de Arbitraje regula el tema del nombramiento del árbitro por las cámaras de comercio. Su texto es el siguiente:

Artículo 25.- Nombramiento por las Cámaras de Comercio

1. Cuando por disposición de este Decreto Legislativo corresponda el nombramiento de un árbitro por una Cámara de Comercio, lo hará la persona u órgano que la propia Cámara determine. A falta de previa determinación, la decisión será adoptada por el máximo órgano de la institución. Esta decisión es definitiva e inimpugnable.

2. Para solicitar a una Cámara de Comercio el nombramiento de un árbitro, la parte interesada deberá señalar el nombre o la denominación social y domicilio de la otra parte, hacer una breve descripción de la controversia que será objeto de arbitraje y acreditar la existencia del convenio arbitral y, de ser el caso, de la solicitud de arbitraje efectuada a la otra parte.

3. Si la Cámara respectiva no tuviera previsto un procedimiento aplicable, la solicitud será puesta en conocimiento de la otra parte por un plazo de cinco (5) días. Vencido este plazo, la Cámara procederá a efectuar el nombramiento. 
4. La Cámara de Comercio está obligada, bajo responsabilidad, a efectuar el nombramiento solicitado por las partes en los supuestos contenidos en los incisos d. y e. del artículo 23 y en el artículo 24, dentro de un plazo razonable. La Cámara únicamente podrá rechazar una solicitud de nombramiento, cuando aprecie que, de los documentos aportados, no resulta la existencia de un convenio arbitral.

5. La Cámara de Comercio tendrá en cuenta, al momento de efectuar un nombramiento, los requisitos establecidos por las partes y por la ley para ser árbitro y tomará las medidas necesarias para garantizar su independencia e imparcialidad.

6. En el arbitraje nacional, la Cámara de Comercio efectuará el nombramiento siguiendo un procedimiento de asignación aleatoria por medios tecnológicos, respetando los criterios de especialidad.

7. En el arbitraje internacional, tratándose de árbitro único o del presidente del tribunal arbitral, tendrá en cuenta asimismo la conveniencia de nombrar un árbitro de nacionalidad distinta a la de las partes. ${ }^{1}$

Esta norma constituye una de las novedades de la vigente Ley de Arbitraje, ya que anteriormente, ante casos como este, se establecía que el órgano jurisdiccional debía ser quien designara al tribunal arbitral.

Aparte de las concordancias extranjeras que sobre el particular hemos encontrado, Rubio Guerrero (2011: 318 ss.) hace referencia al Convenio Europeo sobre Arbitraje Comercial — firmado en Ginebra en 1961 - como fuente primaria de nuestro artículo 25. Dicho cuerpo normativo contemplaba en su artículo IV la intervención del presidente de la Cámara de Comercio correspondiente en determinados supuestos relativos al nombramiento y sustitución de árbitros, entre otros. El mismo Rubio Guerrero, además, aborda la importancia de esta innovación al señalar:

[...] existen al menos dos importantes razones para depositar las designaciones residuales en las cámaras de comercio y no en los tribunales ordinarios: i) porque las cámaras de comercio se han encargado de desarrollar arbitrajes entre los comerciantes y hombres de negocios durante siglos; y ii) porque estas designaciones reducen costos de transacción

1 Concuerdan con el artículo 25 de la Ley de Arbitraje peruana (Decreto Legislativo 1071), entre otros: el artículo 19 de la Ley de Arbitraje y Conciliación boliviana, de 1997; el artículo 45 de la Ley de Conciliación y Arbitraje de Honduras, del 2000; y el artículo 16 de la Ley de Arbitraje y Mediación del Ecuador, de 1997. 
para las partes, que ya no tienen que soportar la carga procesal de los tribunales ordinarios para conseguir el nombramiento de un árbitro.

Ahora bien, debemos reconocer que todo el contenido del numeral 25 podría entenderse como el establecimiento de un monopolio a favor de las cámaras de comercio, hecho que llevaría a sostener que, entre otras cosas, los precios o tarifas señalados por las cámaras no van a tener competencia con respecto a otros organismos, con lo que estas entidades podrían abusar de su posición.

Sin embargo, y junto a Rubio Guerrero, no creemos que ello sea así, pues

[...] no estamos hablando del universo de las designaciones de árbitros, sino únicamente de las designaciones residuales, es decir, cuando las partes no hayan cumplido con efectuar una designación que les corresponde y no hayan designado una autoridad nominadora para estos efectos o cuando esta no cumpla con el encargo. Las partes tienen la posibilidad de designar a sus árbitros o designar a una autoridad nominadora que los designe, sin ninguna restricción (2011: 319).

Dicho esto, a continuación haremos el análisis del contenido de cada uno de los incisos del artículo 25 de nuestra Ley de Arbitraje.

\section{Nombramiento del árbitro por una cámara de comercio}

El inciso 1 del artículo 25 de la Ley de Arbitraje establece: "Cuando por disposición de este Decreto Legislativo corresponda el nombramiento de un árbitro por una Cámara de Comercio, lo hará la persona u órgano que la propia Cámara determine. A falta de previa determinación, la decisión será adoptada por el máximo órgano de la institución. Esta decisión es definitiva e inimpugnable".

En primer término, este inciso es el punto de llegada de todos los dispositivos de la Ley de Arbitraje que contienen una norma que establece que será una cámara de comercio la encargada de nombrar al árbitro, incluso si esta labor es realizada de manera supletoria por dicha entidad.

De esta forma, los casos en los que una cámara de comercio será la encargada de nombrar a uno o varios árbitros son los siguientes:

- Cuando una o más partes no designan al árbitro que les corresponde.

- Cuando no hay acuerdo entre las partes para designar al árbitro único, a todos los árbitros o al presidente del tribunal arbitral. 
- Cuando dos árbitros no se ponen de acuerdo en el momento de designar al árbitro que será el presidente del tribunal arbitral.

- Cuando un tercero, a quien se le encargó esta tarea, no cumple con efectuarla.

En segundo término, y ya teniendo claro que estamos en un escenario en el que será una cámara de comercio la encargada del nombramiento del árbitro o los árbitros, la ley establece dos opciones:

- El árbitro o los árbitros serán nombrados por la persona u órgano que la propia cámara determine.

- A falta de previa determinación, la decisión será adoptada por el máximo órgano de la institución.

La primera regla que se debe tener en cuenta es que, en caso de que una cámara de comercio tenga esta labor, deberá designar a una persona o a un órgano para que cumpla con el requerimiento.

Surge aquí una primera interrogante: ¿esta persona $u$ órgano debe necesariamente ser parte de la cámara de comercio? Vale decir, ¿la cámara podrá designar a una persona u órgano ajeno a ella?

Creemos que, en vista de que el texto de todo este artículo se dedica a regular cómo es que una cámara de comercio debe designar a un árbitro, el sentido de la norma debe entenderse como que esta persona $u$ órgano debe ser parte de aquella entidad.

Ahora bien, la norma no establece límites en cuanto a la persona u órgano que la cámara pueda designar. Sin embargo, y como veremos más adelante, existen ciertas pautas que esta persona u órgano deberá tomar en cuenta (aparte de las ya estudiadas exigencias legales).

Por otro lado, este inciso señala que en caso de que no exista una determinación previa (entendemos que esta "determinación previa" se refiere a que la cámara debe tener en su estatuto o en algún reglamento interno una estipulación que establezca que, en casos como este, será tal o cual persona la encargada de elegir al árbitro), la decisión será adoptada por el máximo órgano de la institución.

Sabemos que una cámara de comercio tiene, normalmente, como máximo órgano a su asamblea general. A esta le sigue el consejo directivo, que tiene, además, un presidente.

Empero, y para citar un ejemplo representativo, ello no siempre es así: la Cámara de Comercio de Lima posee, aparte de su asamblea general, un órgano especializado que se denomina Centro de Arbitraje de la 
Cámara de Comercio de Lima, el cual, a su vez, tiene un ente llamado Consejo Superior de Arbitraje, el mismo que, de acuerdo con sus reglamentos y conforme a lo que establece el inciso 1 del artículo en estudio, sería el encargado de nombrar de manera supletoria al árbitro, en defecto de nombramiento y conforme a lo dispuesto por los artículos 23 y 24 de la Ley de Arbitraje.

Es importante recordar que estas normas son, evidentemente, de carácter dispositivo, ya que podría haberse convenido algo distinto en el convenio arbitral.

El inciso en estudio concluye señalando que la decisión que adopte la cámara de comercio a través de la persona u órgano competente -a los efectos de designar de manera supletoria al árbitro- es de carácter definitivo e inimpugnable.

Esta precisión es muy importante en la medida en que no sería correcto proceder a efectuar una revisión de lo señalado, a través del establecimiento de una segunda instancia vía una apelación.

Claro está que si la designación del árbitro vulnera algún derecho de las partes o de alguna de ellas, esta podrá hacerlo saber de inmediato al órgano que efectuó el nombramiento, a efectos de dejar constancia de que el arbitraje se inicia con un vicio de origen. Esta situación podría permitir que aquella parte interponga, posteriormente, un recurso de anulación en virtud de las disposiciones que establece la propia Ley de Arbitraje.

Opinamos que, en efecto, sería poco eficiente que la norma haya planteado que la decisión de la cámara de comercio pueda ser apelada. Sin embargo, si bien es cierto resulta idónea una estipulación como esta en vista de que otorga seguridad jurídica a todas las partes (incluida la cámara), lo cierto es que hubiera sido sensato establecer que aquella decisión pueda ser impugnada vía recurso de reconsideración, pues, en el estado actual de las cosas, la petición o malestar de la parte solamente tendrá por objeto dejar constancia de lo ocurrido y no representará, de ningún modo, la posibilidad de abrir un camino con el objeto de que se pueda remediar el error.

Un típico caso puede ser observado en el hecho de que, por ejemplo, la cámara de comercio designe a un árbitro que tenga una vinculación directa con una de las partes. En este caso, la parte que se sienta vulnerada tendría que recurrir al mecanismo de la recusación, pero todo este trámite podría evitarse si el órgano de la cámara de comercio que hubiese nombrado el árbitro pudiese volver a analizar esa decisión mediante un recurso de 
reconsideración. De ahí que sea importante que se repiense este extremo de la norma y que, en una eventual reforma legislativa, se establezca que aquella decisión pueda ser impugnada vía recurso de reconsideración.

Como vemos, las facultades que se están otorgando a las cámaras de comercio son bastante amplias, notorias e importantes. Pero nos queda la interrogante de si esas facultades constituyen una ventaja para alimentar la celeridad de las actuaciones arbitrales o, más bien, son un arma de doble filo.

Como en todo, estas prerrogativas serán una ventaja en la medida en que la cámara de comercio funcione adecuadamente, se guíe por criterios de moralidad y decencia y respete siempre los principios generales de derecho, así como la legislación vigente. En caso contrario, constituirán un instrumento pernicioso en la medida en que dicha cámara se aleje de estos valores y principios éticos.

\section{Requisitos que debe contener la solicitud}

El inciso 2 del artículo 25 de la Ley de Arbitraje señala:

Para solicitar a una Cámara de Comercio el nombramiento de un árbitro, la parte interesada deberá señalar el nombre o la denominación social y domicilio de la otra parte, hacer una breve descripción de la controversia que será objeto de arbitraje y acreditar la existencia del convenio arbitral y, de ser el caso, de la solicitud de arbitraje efectuada a la otra parte.

En principio, resulta obvio que debe existir una solicitud a la cámara de comercio, a efectos de que esta proceda a realizar el nombramiento supletorio del árbitro.

Dicha solicitud deberá contener una serie de datos que permitan, entre otras cosas, identificar a la contraparte, así como comprobar, de manera preliminar, que la vía arbitral es la acordada por las partes para resolver su conflicto de intereses.

Así, en primer lugar, se debe señalar el nombre o la denominación social de la otra parte, con el objeto de verificar la identidad de la persona natural o jurídica con la que se va a iniciar el procedimiento.

En segundo lugar, se tiene que señalar el domicilio de la otra parte, con el objeto de que se le pueda notificar de una manera adecuada y fehaciente.

En tercer lugar, la norma hace referencia a una breve descripción de la controversia que será objeto de arbitraje. Aquí es necesario subrayar 
que se trata solo de eso: una breve y genérica descripción de lo que será materia de un futuro arbitraje. Es decir, no resulta indispensable señalar los elementos que sí se necesita desarrollar en el documento de solicitud de arbitraje, donde se debe establecer de manera detallada cuáles serían las eventuales pretensiones de la parte demandante en el arbitraje cuyo inicio está solicitando, qué fue lo que exactamente ocasionó la controversia, entre otros puntos.

Por otro lado, esta exigencia resulta adecuada, pues la designación con carácter supletorio del árbitro tendrá que recaer en una persona que revista condiciones de idoneidad, a efectos de ejercer con propiedad el cargo para el cual va a ser nombrada. Si se tratara, por ejemplo, de un arbitraje en materia de contratación pública, se entenderá que deberemos estar en presencia de una persona que debería tener cierta experiencia en ese rubro. De la misma forma, si, por ejemplo, se trata de un arbitraje sobre una materia contractual, sería ideal que el árbitro sea una persona entendida en materia de contratos. Esta es, pues, la razón por la cual el inciso 2 del artículo 25 de la ley exige esa breve referencia a la futura controversia.

En cuarto lugar, este inciso exige que se acredite la existencia del convenio arbitral.

Como se sabe, es de vital importancia que dicho convenio conste por escrito. De hecho, y con el objeto de favorecer la existencia del arbitraje, la propia ley establece en su artículo $13^{2}$ diversos preceptos que otorgan la calidad de convenio arbitral a una serie de actos.

2 Artículo 13.- Contenido y forma del convenio arbitral

1. El convenio arbitral es un acuerdo por el que las partes deciden someter a arbitraje todas las controversias o ciertas controversias que hayan surgido o puedan surgir entre ellas respecto de una determinada relación jurídica contractual o de otra naturaleza.

2. El convenio arbitral deberá constar por escrito. Podrá adoptar la forma de una cláusula incluida en un contrato o la forma de un acuerdo independiente.

3. Se entenderá que el convenio arbitral es escrito cuando quede constancia de su contenido en cualquier forma, ya sea que el acuerdo de arbitraje o contrato se haya concertado mediante la ejecución de ciertos actos o por cualquier otro medio.

4. Se entenderá que el convenio arbitral consta por escrito cuando se cursa una comunicación electrónica y la información en ella consignada es accesible para su ulterior consulta. Por "comunicación electrónica" se entenderá toda comunicación que las partes hagan por medio de mensajes de datos. Por "mensaje de datos" se entenderá la información generada, enviada, recibida o archivada por medios electrónicos, magnéticos, ópticos o similares, como 
Sin embargo, estos preceptos podrían conducir a que exista duda en la cámara de comercio ante la que se solicite el nombramiento, con carácter supletorio, del árbitro, acerca de si se cumple o no con el requisito de que el convenio conste por escrito.

Imaginemos, por ejemplo, que la parte que solicita el nombramiento supletorio del árbitro presenta ante la cámara de comercio un intercambio facsimilar o de correos electrónicos como convenio arbitral. En tal caso, ¿existirá convicción en la cámara de comercio acerca de la existencia de ese convenio arbitral? Creemos, en principio, que no, siendo este uno de los problemas que se podrían derivar de la amplitud, en materia de forma, establecida por la Ley de Arbitraje.

De cualquier manera, se tendrá que estar frente a cada caso para que la cámara pueda, de modo preliminar, acoger como convenio arbitral determinado documento presentado por la parte.

Finalmente, el inciso 2 exige que, de ser el caso, también debe acompañarse la solicitud de arbitraje formulada a la otra parte.

Respecto a este punto, entendemos que la ley se refiere solamente a las situaciones en las cuales ambas partes no recurran de común acuerdo para que se nombre al presidente, sino que sea la parte (o la futura parte) demandante la que recurra a la cámara de comercio, a fin de que la contraparte a quien se ha solicitado el inicio de un arbitraje nombre un árbitro ante, precisamente, la omisión del cumplimiento del deber de nombramiento de dicho árbitro.

pudieran ser, entre otros, el intercambio electrónico de datos, el correo electrónico, el telegrama, el télex o el telefax.

5. Se entenderá además que el convenio arbitral es escrito cuando esté consignado en un intercambio de escritos de demanda y contestación en los que la existencia de un acuerdo sea afirmada por una parte, sin ser negada por la otra.

6. La referencia hecha en un contrato a un documento que contenga una cláusula de arbitraje constituye un convenio arbitral por escrito, siempre que dicha referencia implique que esa cláusula forma parte del contrato.

7. Cuando el arbitraje fuere internacional, el convenio arbitral será válido y la controversia será susceptible de arbitraje, si cumplen los requisitos establecidos por las normas jurídicas elegidas por las partes para regir el convenio arbitral, o por las normas jurídicas aplicables al fondo de la controversia, o por el derecho peruano. 


\section{Notificación de la solicitud a la contraparte}

En el inciso 3 del artículo 25 de la Ley de Arbitraje se establece: "Si la Cámara respectiva no tuviera previsto un procedimiento aplicable, la solicitud será puesta en conocimiento de la otra parte por un plazo de cinco (5) días. Vencido este plazo, la Cámara procederá a efectuar el nombramiento".

Esta norma está delineando cuál es el procedimiento aplicable para la designación por parte de la cámara de comercio.

Es evidente que la solicitud de nombramiento tiene que ser puesta en conocimiento de la contraparte, para que esta exprese lo que convenga a su derecho.

En principio, la contraparte podría, por ejemplo, negar la existencia de la cláusula arbitral y considerar que aquello que se presenta como convenio arbitral es un convenio inexistente o falso, que se trata de un convenio que no reúne las formalidades requeridas por la ley, que el convenio arbitral haya señalado algo distinto con relación al nombramiento supletorio, o, en suma, lo que la contraparte considere conveniente.

Luego de vencido el plazo, con contestación, o sin ella, de la futura parte demandada, la cámara de comercio procederá a efectuar el nombramiento.

Ahora bien, cabe plantear algunas cuestiones sobre la forma en que esta norma ha sido concebida. Este inciso se caracteriza por poseer una estructura condicional, ya que subordina la segunda oración a la primera. En ese entendimiento, de una lectura literal del inciso podríamos concluir que si la cámara respectiva tuviera previsto un procedimiento aplicable, la solicitud no será puesta en conocimiento de la otra parte. Así, nos preguntamos: ¿resulta esto conveniente?

Creemos que lo idóneo es que tenga o no tenga la cámara previsto un procedimiento aplicable, deberá notificar la solicitud a la otra parte para que exprese lo que considere conveniente. Es decir, el inciso tercero debería tener una redacción como la que sigue: "La solicitud será puesta en conocimiento de la otra parte por un plazo de cinco (5) días. Vencido este plazo, la cámara procederá a efectuar el nombramiento".

Así se estaría otorgando las mismas condiciones a la contraparte para que no sienta vulnerado su derecho de defensa, pues, al igual que la parte que solicita la intervención supletoria de la cámara, la contra- 
parte también podría someter a consideración de la cámara algunas exigencias en cuanto a las cualidades del árbitro o, incluso, cuestionar de alguna forma el convenio arbitral presentado.

Además, y siguiendo lo señalado por Rubio Guerrero (2011: 322), la posibilidad de otorgar cinco días a la contraparte podrá permitir que esta "i) comunique que ha cumplido con la designación con anterioridad, en cuyo caso deberá acreditar esta situación; y ii) designar al árbitro dentro de los cinco días. De esa forma, en ambos casos la finalidad de la designación del árbitro está cumplida y no corresponde la intervención de la cámara de comercio".

Por estos motivos, creemos que la primera oración de este inciso debería ser eliminada, pues no tiene sentido supeditar la notificación a la contraparte a la no existencia de un procedimiento aplicable para estos casos.

\section{Obligatoriedad del nombramiento}

Por su parte, el inciso 4 del artículo 25 de la Ley de Arbitraje señala:

La Cámara de Comercio está obligada, bajo responsabilidad, a efectuar el nombramiento solicitado por las partes en los supuestos contenidos en los incisos d. y e. del artículo 23 y en el artículo 24, dentro de un plazo razonable. La Cámara únicamente podrá rechazar una solicitud de nombramiento, cuando aprecie que, de los documentos aportados, no resulta la existencia de un convenio arbitral.

Esta norma establece la obligación de que la cámara de comercio efectúe la designación, obligación que parte de un mandato legal. Es decir, se entiende que aquí no hay un contrato, sino un mandato de la ley sobre las cámaras de comercio.

En segundo término, conviene señalar que al tratarse de un mandato legal (y teniendo en cuenta que una obligación puede nacer de la voluntad de las partes, así como de la ley), ante el incumplimiento de la cámara de comercio se producirá una inejecución de obligaciones, razón por la cual serán aplicables los artículos 1314 y siguientes del Código Civil peruano.

En tercer lugar, y luego de hablar de la naturaleza de la obligación y la responsabilidad de la cámara, cabe hacer mención al "plazo razonable" que la ley establece para el cumplimiento de dicha obligación. 
Recordemos que, en principio, la designación de los árbitros de manera supletoria, se rige por los reglamentos de las cámaras, de modo que mientras se cumpla con los plazos reglamentarios no habrá ninguna posibilidad de que se reclame el pago de daños y perjuicios.

Empero, en la medida en que la cámara exceda sus propios plazos reglamentarios, los daños y perjuicios que cause su demora podrán ser reclamados vía acción de indemnización de daños y perjuicios. Por otra parte, cuando la cámara haya sobrepasado sus propios plazos se entenderá que rechazó el encargo, en virtud de lo señalado por el artículo 24 de la ley.

Por otro lado, si la cámara de comercio no estableciese un plazo en su reglamento, regirá lo dispuesto en el inciso 4 del artículo 25 de la Ley de Arbitraje; es decir, la resolución donde se nombre supletoriamente a los árbitros será emitida y notificada dentro de un plazo razonable.

Como se observa, la expresión "plazo razonable" es ambigua, lo que implica que en algunos casos se pueda llegar a conflictos de interpretación en torno a los alcances y a la posibilidad de haber excedido ese plazo.

Aquí la ley debió establecer que el plazo será de quince días, a fin de que esa ambigüedad desaparezca y se uniformice el tema de los plazos que en materia de nombramiento de árbitros posee la ley.

En cuarto lugar, la última parte del inciso comentado indica que la cámara únicamente podrá rechazar una solicitud de nombramiento cuando aprecie que de los documentos aportados no resulta la existencia de un convenio arbitral.

Sobre este punto, cabe hacer algunas precisiones en torno a la forma del convenio arbitral.

Como sabemos, la regla general en relación con la forma del convenio arbitral era, hasta hace unos años, muy clara: solo podrá considerarse como convenio arbitral todo documento que contenga la voluntad de las partes por escrito y que se encuentre firmado por ellas. Hoy, sin embargo, esta exigencia es bastante relativa y, hasta cierto punto, se ha convertido en un eufemismo.

Roca Martínez señala que "si bien hay libertad formal del convenio arbitral, no puede decirse que haya desaparecido la forma como requisito del convenio arbitral. La forma escrita debe entenderse de una manera amplia (cuando resulte del intercambio de cartas, o de cualquier 
otro medio de comunicación que deje constancia documental de la voluntad de las partes de someterse a arbitraje)" (1992: 147).

Recordemos que según el artículo 144 del Código Civil, cuando la ley impone una forma y no sanciona con nulidad su inobservancia, dicha forma constituye solo un medio de prueba de la existencia del acto.

Así, cuando se establezca el seguimiento de una determinada formalidad, pero - a su vez - el no seguimiento no se sanciona con nulidad, estaremos en presencia de un acto ad probationem. Entonces, conforme a la normativa general, puede sostenerse que el convenio arbitral escrito es un acto ad probationem y no solemne. "Un convenio arbitral que no hubiera sido formalizado por escrito no estaría viciado de nulidad; no obstante, podría presentar graves inconvenientes. Sin embargo, la escritura o no del convenio arbitral tendrá escasa importancia, por cuanto lo verdaderamente relevante es la existencia de la voluntad de las partes" (Roca Martínez 1992: 148).

Con la adopción de esta fórmula, nuestro país pasa a integrar las leyes de arbitraje que han ido flexibilizando la forma del convenio arbitral.

Así, son precisamente estas excepciones - contenidas en el artículo 13 de la Ley de Arbitraje - las que podrían suscitar algunos inconvenientes en el momento en que la cámara evalúe los documentos aportados por la parte y dude sobre la existencia de un convenio arbitral.

Sin embargo, y sin perjuicio de lo señalado, pensamos que cuando el inciso 4 del artículo 25 de la Ley de Arbitraje se refiere a la posibilidad de que la cámara no nombre supletoriamente al árbitro al verificar la inexistencia de un convenio arbitral, se debe entender que alude a una inexistencia material, vale decir, que la cámara de comercio no tiene constancia sobre la realidad física de este documento.

Ante un convenio arbitral presentado por una de las partes, una cámara de comercio no podrá, en ningún caso, deducir la inexistencia como si fuera tribunal de justicia. Lo único que podría hacer es verificar la no existencia del convenio arbitral dentro de la documentación aportada por la parte que solicita el nombramiento supletorio del árbitro. Lo contrario significaría entrar a sustituir las funciones que, de acuerdo con la Constitución y la ley, son propias de los tribunales ordinarios y de los tribunales arbitrales, a efectos de declarar nulidades e inexistencias (estas últimas, como se sabe, reciben en el derecho peruano el tratamiento de una nulidad). 
Ahora bien, ¿qué pasará cuando la cámara rechace intervenir en el nombramiento de un árbitro? ¿Qué camino tiene que seguir el interesado en llevar adelante el arbitraje? Recordemos que el inciso 1 del artículo 25 de la ley establece que las decisiones de las cámaras de comercio son definitivas e inimpugnables.

El camino que le quedará a la parte interesada será el de iniciar un litigio judicial (ya que no va a poder iniciar el arbitraje) mediante un proceso ordinario de declaratoria de convenio arbitral, en donde su contraparte tendrá que exponer sus argumentos. Sólo al término de este proceso, y si la demanda es declarada fundada - vale decir, si el órgano jurisdiccional ordinario declara que existe convenio arbitral-, las partes podrán regresar al fuero arbitral.

Por otro lado, y en este mismo escenario, si la parte que vio frustrada la designación del árbitro (debido a que la cámara resolvió que no existía convenio arbitral) inicia un proceso en sede judicial, es evidente que como demandante no podrá deducir la excepción de convenio arbitral a su favor. Lo que sí puede ocurrir es que la otra parte, que pudiera tener interés en que el problema se ventile ante tribunales arbitrales, deduzca dicha excepción. Es sólo en este caso en donde cabría la excepción de convenio arbitral.

Finalmente, cabe indicar que el incumplimiento de esta obligación podría obedecer a diversas circunstancias; entre otras, por ejemplo, a un conflicto de intereses.

Imagínese que una de las partes del arbitraje sea la cámara de comercio en donde se tramita la designación supletoria del árbitro; es evidente que tal designación (si antes no se estableció la nulidad de la cláusula del convenio arbitral que establecía aquello) sería nula, pues la cámara de comercio estaría actuando como juez y parte.

En casos así se debería entender que la cámara de comercio ha rechazado el encargo y no cabría hablar de una responsabilidad, ya que la omisión no obedecería a una falta de diligencia, sino a causas debidamente justificadas.

Una alternativa de solución sería que recién en casos como este (que difícilmente existirán) la ley faculte a un juez civil para que sea él quien realice el nombramiento del árbitro. 


\section{Exigencias que la cámara deberá tener en cuenta en el momento del nombramiento}

Por su parte, el inciso 5 del artículo 25 de la Ley de Arbitraje señala: «La Cámara de Comercio tendrá en cuenta, al momento de efectuar un nombramiento, los requisitos establecidos por las partes y por la ley para ser árbitro y tomará las medidas necesarias para garantizar su independencia e imparcialidad".

En principio, lo contenido en este inciso es de suma importancia, pues las partes o la propia ley podrían haber establecido algunos requisitos para quien sea designado como árbitro. Por ejemplo, si las partes decidieron que los árbitros revistan necesariamente la condición de especialistas en derecho mercantil, la cámara debería cuidar que la elección se realice entre expertos en dicha materia.

No está de más dejar en claro que las ternas o listas de especialistas que las cámaras de comercio posean deberán reflejar la verdadera especialidad y experiencia de dichos árbitros. Decimos esto porque podrían presentarse casos en los que la experiencia en la relación de árbitros expertos en una materia específica no sea la suficiente.

Ahora bien, cuando el inciso comentado se refiere a los requisitos establecidos por la ley, naturalmente hace referencia a un arbitraje de derecho. En este caso, los árbitros necesariamente tendrán que ser abogados, independientemente de si están colegiados o no y de si son peruanos o extranjeros.

Por otro lado, el mismo inciso establece que las cámaras de comercio tomarán las medidas necesarias para garantizar la independencia e imparcialidad del árbitro que vayan a nombrar.

Esto significa que en la designación no deberán participar como candidatos personas que puedan tener - de manera manifiesta - algún conflicto de interés con las partes o con sus representantes, o encontrarse, en general, dentro de las incompatibilidades señaladas por la Ley de Arbitraje, de modo tal que el nombramiento se encuentre viciado o pretenda favorecer los intereses de una de las partes.

En ese caso, la cámara de comercio deberá tener en cuenta y analizar la información que maneje preliminarmente, a fin de evitar que se produzcan situaciones como esta. 


\section{Forma de la asignación}

El inciso 6 del artículo 25 del Decreto Legislativo 1071 establece: “En el arbitraje nacional, la Cámara de Comercio efectuará el nombramiento siguiendo un procedimiento de asignación aleatoria por medios tecnológicos, respetando los criterios de especialidad".

Como se sabe, los mecanismos de elección de árbitros son de lo más variados, en la medida en que se trate de una asignación aleatoria y no de una asignación por méritos. Decimos esto porque una asignación por méritos - por más que se diga lo contrario - siempre va a ser subjetiva y va a permitir la posibilidad de que la cámara de comercio manipule el resultado.

Respecto a los criterios de especialidad, el mecanismo de designación tendrá que ser lo suficientemente transparente; incluso, para tener la certeza y garantía de ello, se debería requerir la presencia de un notario público que dé fe de la imparcialidad y legalidad del sorteo.

De hecho, creemos que si una de las partes exige la presencia de un notario público para que verifique que el mecanismo de designación aleatoria sea transparente, la cámara deberá aceptar el pedido. Por el contrario, si esa solicitud no fuera amparada, dicha entidad se colocaría en una situación que podría dar lugar a diversos cuestionamientos, pudiendo ser demandada por la parte que cuestionó la transparencia, debido a no haber sido objeto de un trato igualitario y haberse vulnerado su derecho de defensa.

\section{Nombramiento del árbitro por una cámara de comercio en un arbitraje internacional}

Por último, en el inciso 7 del artículo 25 de la Ley de Arbitraje se señala: "En el arbitraje internacional, tratándose de árbitro único o del presidente del tribunal arbitral, tendrá en cuenta asimismo la conveniencia de nombrar un árbitro de nacionalidad distinta a la de las partes".

En principio, conviene expresar que esta norma tiene carácter dispositivo, pues se habla de "tener en cuenta la conveniencia" de nombrar a un árbitro de nacionalidad distinta a la de las partes.

Creemos que el sentido de este precepto es garantizar la equidad dentro del procedimiento arbitral, en la medida en que, si bien es cierto el criterio de nacionalidad no implica parcialidad, compartir la naciona- 
lidad con alguna de las partes podría hacer que el árbitro tenga una situación de mayor cercanía que un árbitro de nacionalidad distinta.

\section{9. ¿Existe un monopolio a favor de las cámaras de comercio para el nombramiento de árbitros?}

Si se leen aisladamente los artículos 23 y 25 de la Ley de Arbitraje, podría pensarse en la existencia de un monopolio legal establecido por dicha ley, a favor de las cámaras de comercio, para el nombramiento de los árbitros cuando se configuren los supuestos de hecho establecidos en dichos artículos.

Sin embargo, creemos que ese monopolio legal no existe, en vista de que la Ley de Arbitraje consagra de manera clara y explícita el principio de autonomía privada, con el objeto de que sean las partes quienes tengan la primera opción de moldear sus relaciones y, en tal caso, establecer la forma en que el árbitro que solucionará su conflicto será elegido.

Así, cabe poner énfasis en el hecho de que la Ley de Arbitraje establece de manera residual la actuación de las cámaras de comercio para tal fin. Y creemos que ello es correcto, porque estas instituciones, a diferencia de muchas otras, poseen cierta reputación en el ámbito comercial y han ido ganando, con el paso de los años, respeto y reconocimiento por la labor que vienen desarrollando.

Con lo señalado no queremos decir que no existan instituciones arbitrales serias y responsables en nuestro país, que puedan cumplir esta labor de manera satisfactoria, pues de hecho las hay. ${ }^{3}$

Lo que deseamos poner de manifiesto es que no tendría sentido modificar esta norma, pues debe reconocerse que las instituciones arbitrales serias y reconocidas en nuestro medio son pocas y no tendría sentido que la ley permita a cualquier institución contar con la importante tarea de elegir al árbitro, pues de este dependerá, en última instancia, el éxito del arbitraje.

Es decir, si no se encomendara - en última instancia - a las cámaras de comercio esta labor y se dejara que esta sea cumplida por, por ejemplo, una institución que existiese en el lugar del arbitraje o por una que

3 Ejemplos de instituciones arbitrales serias, confiables y responsables, en el Perú, son el Centro de Arbitraje de la Pontificia Universidad Católica del Perú y el Centro Internacional de Arbitraje de la AmCham Perú, entre otras. 
se encuentre en el lugar de celebración del convenio arbitral, podría suceder que esta no tuviera la suficiente experiencia para ello o que, incluso, nos encontráramos ante una institución que solo se ha creado con fines que no obedecen al sentido de la norma, sino que más bien se deben a intereses particulares.

El carácter residual de esta fórmula legislativa - aplicable solo en casos extremos - se puede observar en lo establecido por el artículo 24 de la Ley de Arbitraje, cuando señala:

Si la institución arbitral o el tercero encargado de efectuar el nombramiento de los árbitros, no cumple con hacerlo dentro del plazo determinado por las partes o el reglamento arbitral aplicable o, en su defecto, dentro de los quince (15) días de solicitada su intervención, se considerará que rechaza el encargo. En tales casos, el nombramiento será efectuado, a falta de acuerdo distinto de las partes, siguiendo el procedimiento previsto en el inciso d. del artículo 23.

En ese sentido, se deberá leer y entender de manera sistemática el derecho-deber que poseen las cámaras de comercio para nombrar árbitros de manera residual, interpretando conjuntamente los numerales 23, 24 y 25 de la Ley de Arbitraje peruana.

\section{Bibliografía}

Roca Martínez, José María (1992). Arbitraje e instituciones arbitrales. Barcelona: J. M. Bosch.

Rubio Guerrero, Roger (2011). “Nombramiento por las cámaras de comercio", en Comentarios a la ley peruana de arbitraje. Tomo I. Lima: Instituto Peruano de Arbitraje. 